Patrick Cohendet*, David Grandadam, Raphaël Suire

\title{
Reconsidering the dynamics of local knowledge creation: Middlegrounds and local innovation commons in the case of FabLabs
}

https://doi.org/10.1515/zfw-2020-0042

Received: December 01, 2020; accepted March 15, 2021

\begin{abstract}
This contribution investigates the dynamics of knowledge creation at the local level, building, in particular, on the interactions between formal and informal entities. Two theoretical constructions are brought together in order to do so: the middleground concept and the notion of commons. By associating these two concepts, the goal is to introduce a revised perspective on local dynamics of knowledge, which details how informal and formal entities interact with one another in order to drive local ideation processes and how these processes are structured in order to generate innovative outputs. The case of FabLabs is drawn upon in order to illustrate how the middleground and commons concepts can be mobilized to describe and better understand these local dynamics of knowledge creation.
\end{abstract}

Keywords: knowledge, middleground, local innovation commons, FabLab

JEL codes: O32, 031, R58

\section{Introduction}

This paper aims at analyzing the processes by which new developments of ideas and artifacts crystallize at the local level. Our view is that the dynamics of knowledge formation at the local level requires an in-depth analysis of the interactions between formal and informal entities. A formal organization, such as a private firm, an R\&D unit, or a government facility, has an explicitly coordinated structure defined to fulfill business or administra-

\footnotetext{
*Corresponding author: Prof. Patrick Cohendet, Mosaic, HEC Montreal, International Business Department, Montreal, Canada, E-Mail: patrick.cohendet@hec.ca Dr. David Grandadam, Mosaic, HEC Montreal, Montreal, Canada, E-Mail: david.grandadam@gmail.com Prof. Raphaël Suire, LEMNA, University of Nantes, Departement of Business Administration, Nantes, France, E-Mail: raphael.suire@univ-nantes.fr
}

tive purposes. Individuals are merely functional parts of this overall structure and their roles and procedures are formally and rationally planned by top management. In contrast to formal structures, informal structures, such as communities, cliques, clans or associations, are not the result of an intelligent design, but emerge from repeated interactions between agents who share an expression of voluntary work around a common passion. That is, information is exchanged with a minimal set of rules that specify exchange contents or modalities.

Main theoretical constructs in economic geography, such as industrial districts, geographical clusters or local systems of innovation (Markusen, 1996; Maskell and Malmberg, 1999; Asheim and Gertler, 2005; Lundvall, 2007; etc.), have mostly focused on the interactions between formal organizations as the main sources of the local knowledge creation process, and have often tended to overlook the role of the informal. Since the pioneering work from Saxenian (1994), however, the integration of informal entities in processes of knowledge creation is gaining importance, particularly when applied to a local context. An increasing number of important contributions (Amin and Cohendet, 2004; Bathelt et al., 2004; Grahber, 2004; Storper, 2005, Lorenzen and Mudambi, 2013) have emphasized the role of the informal and of various forms of communities in the dynamics of knowledge formation at the local level. Yet, the precise modalities of interactions between the formal and the informal remain to be specified.

In our perspective, the creation of new knowledge does not exclusively rely on exploration strategies of formal (or established) actors, but also relies on exploration behaviors by informal agents, who experiment what is possible (or, in some cases, impossible). Rational formal actors have no incentive (or have little incentive) to seek and find what may be difficult to produce and/or hard to sell, which is why experimentation processes nested in the creation of shared platforms of interaction find their justification.

In a recent series of academic works, the interactions between formal organizations and informal actors, have been analyzed through the notion of "middleground", which is viewed as a meta-platform for groups and com- 
munities linking the knowledge production activities of an informal "underground" with the formal exploitation of organizations and institutions of an "upperground" (Simon, 2009; Cohendet et al., 2010; Grandadam et al., 2013; Avdikos, 2015; Lange and Schüßler, 2018). The underground is composed of individuals who are not immediately linked to the commercial and industrial world, but who potentially provide the upperground with important sources of generation (and regeneration) of new knowledge, or key opportunities to test and develop new business models or disruptive innovations that may be of high value for firms. In such a perspective, the key issue is the quality and degree of connection between the underground and the upperground. That is, the key role of the middleground is to generate the indispensable intermediary cognitive tools and devices for the process of knowledge creation to unfold, by providing situated peer reviews and selection mechanisms and by "knitting" diverse communities and their knowledge bases together in order to materialize ideas.

Grandadam et al. (2013) suggest that the middleground is characterized by four key components: "places" (the realm of near, intimate and bounded relations, physically established), "spaces" (the realm of far and fluid relations, cognitive constructions, challenges, orienting questions, "episteme”, etc.), "projects" (concrete activities to engage local communities in conversations, work together, and actualize and materialize ideas) and "events" (that open the small local worlds to potential users and consumer audiences, and to new external influences). Each of these components (places, spaces, projects and events) requires some form of physical presence for people to meet, to share their experience or to participate in collective events. Thus, in this perspective, inasmuch as these components are present, the middleground will enable localities to equip themselves with the means to generate nodes of interaction between the formal and the informal. These connections will, in turn, allow ideas generated from the informal entities of the underground to be progressively enriched and validated, to eventually become formal entities, such as start-ups, but also reciprocally to permit ideas from the formal structures of the upperground to stimulate and challenge the diverse communities in the underground.

The middleground analysis constitutes a first step towards understanding innovation processes in a local setting where formal and informal actors interact. The existing literature on this notion, however, does not focus on what agents actually do, and how the local ideation processes that eventually will lead to innovative outputs are actually carried out and structured when passing through the middleground. The literature on the middleground tends to consider that the different components that constitute the middleground, along with their history, are given, such that the type of relationships between the different stakeholders, formal or informal, are passed into silence. In such circumstances, and in our understanding of the middleground concept, while places, spaces, projects and events are presented as providing the grounds for creative and ideation processes to unfold, they are far from guaranteeing that ideas or concepts will indeed and effectively be created and eventually reach the market.

For all the above reasons, we here offer to complete our understanding of the local formation of ideas and innovation by complementing the middleground concept with the recent literature on innovation commons, as introduced by Ostrom (1990) and later taken over by Potts (2018), in particular. This approach aims at explaining how resources are developed through citizen-level collective action and without government intervention. More importantly, the innovation commons can be seen as an institutional arrangement in which different stakeholders (formal or informal) engage in collective action and develop rules to generate, share and govern innovation resources.

Our view is that while the notion of middleground focuses on the local platforms of interactions which facilitate the interactions between formal and informal entities ("how the creative agents meet and learn?"), the notion of innovation commons emphasizes the actions taken by heterogeneous agents to build governance mechanisms in order to foster innovations ("what the creative agents do?”). In its current developments, the middleground concept does not explain how informal groups can build governance mechanisms for mutual cooperation to create a common pool of distributed resources in order to transform new ideas into an innovation. Thus, in the understanding of the fabric of local knowledge, we can learn from these approaches to better understand the conditions that favor the building of local knowledge, but we do not really know what the informal entities, individual agents or communities actually do together with the formal entities to build new knowledge at the local scale. By combining the middleground and commons literature, our goal, therefore, is to unpack what we see as a blurry concept and introduce a revised perspective on local dynamics of knowledge and innovation, which we see as a theoretical missing piece that adds to our understanding of these dynamics.

To illustrate this conceptual framework, we have chosen the example of Fablabs as an ideal type of mid- 
dleground whereby local innovation commons emerge from a community of passionate local actors who elaborate common institutional arrangements and appropriate governance structures to promote their knowledge creation efforts. Drawing on the global principles of the maker culture and of the FabLab MIT Charter, and inspired by an open-source culture, local communities, through their specific institutional arrangements, shape the nature and mode of functioning of each FabLab. The local innovation commons on which each FabLab is based are built around the resources brought by the local actors and modes of governance they have decided to adopt. From these initiatives, the commons can take shape. In other words, a FabLab can be considered as an element of the middleground, inasmuch as the projects and events that are developed within are structured on local commons and respect the open-source governance principles that make up the MIT Charter. Of course, the type of commons that govern this place or space, along with the projects and events that are developed within may differ from one FabLab to another, but this will not alter its fundamental nature. The specific local commons drives the type of outcomes and spillover effects that will emerge out of the FabLab: some FabLabs aim at developing start-ups for the market, while others will mostly focus on exchanges of experience and best practices.

The paper is structured as follows. In a first part, we investigate, in detail, the notion of innovation commons. A second part aims at the integration between the recent approaches on the role of the informal in the building of local knowledge with the notion of innovation commons. We illustrate these views using the specific case of FabLabs and maker ethos, in a third part. Here, we emphasize the importance of local interactions, along with their global ramifications, focusing more specifically on the specific institutional arrangements supporting ideation and knowledge creation dynamics. We conclude with a detailed discussion of our perspective and offer some remarks for future research on these topics.

\section{Key intermediaries in the formation of knowledge: the innovation commons}

In this contribution, we aim at adding to the understanding of the local building of innovation by highlighting the key role of the local innovation commons as a central concept explaining how ideas are turned into innovative outputs in a local context.

The importance of a common structure of innovation, viewed as a shared platform between diverse stakeholders with divergent interests allowing collective learning (Capello, 1999), has been repeatedly emphasized in the literature since the work on collective invention by Allen (1983). As an example, Garud and Van de Ven (1989) have developed the concept of "infrastructure of innovation", viewed as a quasi-common good, co-built by heterogeneous actors (private firms developing similar, competing or substitute technologies, but also other actors such as public entities or informal communities) in order to drive the innovation dynamics in a given industry. The shared common, in this perspective, includes "(i) institutional arrangements to legitimate, regulate and standardize a new technology, (ii) public resource endowments of basic scientific knowledge, financing mechanism and a pool of competent labor, as well as (iii) proprietary R\&D, manufacturing, marketing and distribution functions that are required to develop and commercialize an innovation" (Van de Ven, 1993: p. 27).

Along these lines, the building of an industry can be seen as the result of a generative process, which emerges through the co-building of common resources. Each participant to a given industry is exposed to a tension between the need to focus, on one side, on the management of the internal organization and, on the other side, on the contribution to the collective creation of resources needed for the development of the whole industry.

This work finds an echo in a recent stream of literature, which draws on the work of Elinor Ostrom (1990) and introduces the notion of innovation commons (Allen and Potts, 2016).

Generally speaking, the commons can be defined as sets of resources managed collectively without there being a specific rightholder over them. For example, the environment, fisheries, culture, but also free software, information and knowledge are often governed by commons. Initially, the importance of the collective management of natural resource commons (forests, urban heritage, etc.) was highlighted in the work of Elinor Ostrom (1990) as a reaction to the "tragedy of the commons" (Hardin, 1968). The traditional view from economists was that in the absence of either private property rights or centralized management by the public authorities, individualistic user behaviors would inevitably lead to a degradation of natural resource common goods. Ostrom severely questioned these conclusions and advocated that neither centralized management by the state nor a free market can really protect these common natural resources. Her research emphasizes the 
advantage of institutional arrangements managed collectively by an appropriate governance structure that enables a directly affected community to aim for the orderly exploitation of the resource to ensure both the well-being of its members and the sustainability of the resource. Commons can accordingly be seen as a collective action governance mechanism over a common pool of resources shared by a group of people that is vulnerable to social dilemmas.

Building on her seminal work, which challenges the establishment of traditional property rights based on the principle of exclusion, other commons have received increasing attention, in particular in what is known as knowledge commons. Ostrom herself (Hess and Ostrom, 2007) attempted to establish the specificity of knowledge commons, highlighting their own characteristics: they are made up of non-rival goods as opposed to the commons; they can provide broader access thanks to digital media; and, finally, the governance of which they are the object is oriented not towards conservation (as is the case for natural resources) but towards the aggregation of ideas. This approach aimed at explaining how knowledge resources are developed through citizen-level collective action and without government intervention while still relying on a characteristic institutional context. The emblematic case of the Wikipedia platform illustrates the growing importance of knowledge commons.

As a subset of the knowledge commons, the innovation commons (Potts, 2018; Allen and Potts, 2015, 2016; Cutcher-Gershenfeld and Lawson, 2020) are defined as the result of collective action destined to contribute shared resources, knowledge and information to create an "innovation resource pool” (Potts, 2019). This stream of literature focuses on the institutional origin of new technologies when self-organizing groups of technology enthusiasts develop effective governance rules to pool distributed information resources. Innovation commons are viewed as rule-governed spaces for solving social dilemmas inherent in sharing knowledge, information and other resource inputs into innovation. In other words, they consist in a set of governance mechanisms in which different stakeholders (even if competing) engage in collective action and cooperate in order to nurture the dynamics of innovation by developing rules to create, share and govern innovation resources. They tend to emerge spontaneously from the mutual accommodation and agreements made between communities of interacting agents. Such common arrangements are efficient in coordinating knowledge because other organizational forms, such as hierarchies (firms, or, in some cases, governments) and markets (property rights, price signals), are often poorly equipped at dealing with this combination of highly distributed, tacit and uncertain resources (Tirole, 2017).

The innovation commons exhibit different features than that of other knowledge commons: most notably, they contain resources dedicated to the advancement of knowledge, not simply to its aggregation. An emblematic example of innovation commons is the creative commons licensing, devoted to educational access and expanding the range of creative works available for others to build upon legally. Following the work of Allen and Potts (2015), the innovation commons consist in institutional mechanisms, which serve and ease the process of entrepreneurial discovery (Hausmann and Rodrik, 2003), while also enabling the transformation of ideas into innovative outputs. Entrepreneurs wishing to develop a new idea or technology may thus contribute to the innovation commons, while, at the same time, serving the projects and creative endeavors of other actors. In exchange, the entrepreneurs will be gratified with information pieces that may help them solve the puzzles that they may face. This suggests that the innovation commons are mutually beneficial for the actors that engage in their development and maintenance by reducing uncertainty. In this way, entrepreneurs may participate and take part in other institutional contexts - including markets and hierarchies. The innovation commons, therefore, are not just social provisioning or peer production mechanisms, but constitute, instead, platforms, which, in this case, enable the realms of formal and informal to be brought together, in an effort to generate (common) knowledge externalities.

\section{The local innovation commons at the core of local knowledge creation}

All the works mentioned above highlight how a common infrastructure of innovation (or commons) can support the formation of an industry, but these works do not incorporate a spatial dimension. Focusing on the development of information technologies, the literature on innovation commons regularly highlights contemporary examples of innovation commons that have a widespread diffusion, such as the internet, blockchain technology, hackerspaces, cryptocurrencies, 3D printing technology, etc. These works generally do not consider the dynamics of idea formation in a local context. As emphasized by Dekker (2020: p. 663-664): 
"Potts overlooks the importance of 'places', something that has received ample attention in the study of creative communities and scenes. From the Parisian salons (Impressionism) to the Viennese coffeehouses (Sezession) and from the mixed cultural clubs of New Orleans (jazz) to the metros of New York (graffiti), specific places gave birth to scenes and new genres. Potts has lots of interesting things to say about a culture of innovation in which 'the new' is tolerated, but he pays virtually no intention to the importance of meeting places and their characteristics, although innovation policy for the creative industries has long recognized the importance of place, from Richard Florida's creative cities to the more recent emphasis on place-making".

In economic geography, the idea that economic action and the behavior of economic actors are shaped by common local conventions, norms, habits, routines and other characteristics of social context, has been widely accepted and diffused (see Amin and Thrift, 1992; Storper, 1997; Capello, 1999; Cumbers et al., 2003; Giuliani and Bell, 2005; Bathelt and Glückler, 2011). Storper (1997), in particular, argues that firms and organizations become attached to particular territories through the development of "untraded interdependencies" that are rooted in the development of regionally specific conventions and routines. Those regions that can build a stock of "relational assets" through routine interactions between formal and informal actors will develop a capacity for learning that enables them to adapt to change within an increasingly uncertain economic environment. This is where the analysis of the middleground, seen as a combination of places, spaces, projects and events, is useful, by highlighting the importance of diverse platforms of interactions that allow agents to meet and to learn to enrich and develop their innovative efforts.

Our view is that the in-depth understanding of local knowledge creation processes within the middleground requires us to also take into account the institutional arrangements between creative agents to explain the trajectories of ideas that transit through the middleground and eventually turn into innovative outputs. As we see it, the top-down and bottom-up dynamics of local knowledge creation, along with the horizontal dynamics that emerge and are sustained thanks to the middleground are strongly related to the construction of "local innovation commons", viewed as invisible and infinite sources of locally-embedded and shared resources, linking and facilitating interactions or joint initiatives between the formal and informal entities, and out of which a range of externalities will be expected to blossom. The innovation commons are nodes of multiple relations which are co-constructed by and enable the formal and the informal to interact with one another, and, more importantly, which open the way to new governance mechanisms that are neither fully public, neither fully private, but still aim at the orderly exploitation of resources. In our view, local knowledge creation dynamics taking place at the middleground level are rooted in the creation and maintenance of local commons, which, when duly stimulated and promoted, should be expected to act as important generative sources of innovation for regions.

Based on the above, and in line with the work of Bollier and Helfrich (2014), in particular, the local innovation commons consist in three elements:

1) A community of formal and informal actors or entities who act in a common goal.

2) Quasi-public resources that are mostly non-rival and non-exclusive. These local resources are the people, knowledge, tools and capital, which are used as inputs to the ideation process. These resources all contain elements of excludability and/or rivalry, such that governments or the private sector are usually seen as the sole providers of these resources globally. Locally, however, these resources may change nature and may therefore equip a specific locality with the means to foster the generation of ideas and further innovation.

3) Various institutional arrangements, including multiple habits, norms, conventions, or routines, that may equip the given resources with non-excludable and/or non-rival features, thus better serving the local community's needs. As elements of innovation commons, these arrangements are built and made available within the locality, and ultimately enable individual and collective learning. They are maintained and enriched by collective debates, interactions and feedbacks arising from explorative undertakings. These institutional arrangements consist in the reciprocal and voluntary micro-actions (including various forms of trades, barters, exchanges and gifts) that are regularly carried out by the formal and informal entities present locally, and that provide other actors with new resources, while also facilitating the access, use, transformation and transmission of these resources, without clearly identified property rights. More importantly, they consist in a system of rights and obligations that endows the actors with entitlements to use, diffuse, replicate or transform common resources, while also ensuring the long-term regeneration of these same resources.

These three elements are fundamental characteristics of the commons, which define the nature of the latter, and, as such, may exist on their own. Our suggestion is that, when anchored to a rich middleground, they equip the 
latter with the means to generate dynamic nodes of interaction between the formal and the informal, and thus will accompany the local trajectories of ideas.

The local innovation commons can be viewed as particular forms of governance modes, which are intended to facilitate the access and availability of resources to the members of the collective. That is to say that, by combining communities, resources and institutional arrangements, the local innovation commons establish a truly open, dynamic and shared localized ecosystem that favors the implementation and reinforcement of a collaborative and integrated innovation value chain, articulating knowledge production, generation, experimentation and validation of new ideas, as well as the concrete development of innovative projects. The components of local innovation commons (resources and institutional arrangements) thus reinforce the middleground to explain the dynamics of local knowledge creation. Again, the middleground cannot be sustained on its own. Without the commons, the middleground is simply an aggregation of places, spaces, projects and events with no real substance - we might say, in this case, that these places, spaces projects and events do not constitute an actual middleground. Such arrangements may simply depend on a small number of active actors who may not represent the interests of local communities, while also leading to various forms of disengagement, which may limit the locality's capacity to generate opportunities for the community. In these situations, there would be no understanding of what people actually do within the so-called middleground to transform ideas into innovative outputs. By contrast, when local commons are rightfully combined to and equip the middleground, they enable people to meet and experience mutual learning, while also enabling the process of knowledge creation to fully unfold.

By contributing (intentionally or unintentionally) to the commons through these intermediary middleground platforms, the formal actors (including companies and their suppliers) along with the informal actors (such as groups and collectives) develop their collective capacity to create knowledge, and thus contribute to build and reinforce the locality in which they officiate. In doing so, they bring value to the locality's collective organization beyond the value created by each individual. As a result, when rightfully combined to intermediary platforms of interaction, the commons define how resources are governed and distributed within a locality. More importantly, they characterize how innovation capacities are built locally and, in turn, contribute to generate knowledge externalities.
Various forms of middleground platforms (based on the middleground components) have been developed since the 90s and have succeeded in structuring themselves around commons. Examples of these platforms include several openlabs, makerspaces, hacker spaces, and so on. In the following we examine in detail the development of one of these platforms, or, more precisely, one type of place which has succeeded in acting as a middleground platform: FabLabs. We focus on FabLabs and maker ethos as an ideal type and a contemporary example depicting the emergence of local innovation commons, with its potential benefits for local knowledge creation, but also with its limits.

\section{FabLabs and maker ethos in the building of local innovation commons}

The FabLab movement originated in the classroom of Professor Niels Gershenfeld from the MIT in the early 2000s. The very basic philosophy of his proposition was to offer students opportunities to help turn ideas into things. In his own words, the course came with tools to allow any student enrolled in the class to "make almost anything" including "artistic extravaganzas", while also "being an actor rather than just a spectator of a technological world" (Gershenfeld, 2005). What was remarkable and astonishing with such an offer was that the contents of the class were not written a priori. Students were considered primarily as makers learning by themselves and with others. They discovered how technological tools based on open-source knowledge (3D printer, open electronic hardware, laser cutter, etc.) work and how they could handle these tools for their own purposes (building, prototyping, repairing, etc.), but with a strong incentive to share knowledge acquired through this process of making. The class, in that sense, aimed to produce specific outcomes: learning by oneself and learning with others by interacting led to doing by oneself, but also to doing with others. That is, within the FabLab, students used technological tools at hand, firstly to make and learn, and, secondly, to create an open and common pool of information and knowledge (Suire, 2019). In that respect, all the stakeholders of this academic program co-produced innovation commons.

As stated by Gershenfeld, open-source culture is the invisible rule of a FabLab (Walter-Herrmann and Büching, 2014). This means that all the pieces of knowledge pro- 
duced in a Fablab, whatever is produced, should be documented as far as possible and the recipes should be freely available for other makers, wherever they are located, whoever they are. This means, here, that a maker can be an individual belonging to a formal organization (a large company, a city, a museum, etc.), but can also come from a less organized or informal collective, and, in some cases, be a "simple" citizen.

These basic principles constitute the FabLab MIT Charter and the manifesto of the maker culture (Hatch, 2013). Anyone can open a place and name it a FabLab as long as the initiator posts the MIT Charter on the wall. By the end of 2020s, there were almost 1500 FabLabs ${ }^{1}$ following the MIT Charter around the world. A FabLab has to be open to all (at least half a day per week), has to participate in the life of the network, and must have a minimum set of common machines (in order to encourage the reproducibility of projects from one FabLab to another). By following, the basic principles of the MIT Charter, they altogether constitute a global inter-organizational community with different localized anchorages. Sub-communities are always an option, particularly to respond to local needs (educating, repairing, empowerment, health, etc.). Whatever the case, a FabLab is an infrastructure (and in some cases, a middleground) addressed to a large variety of local objectives, which consumes knowledge coming from a global pool, but also contributes to this same pool by exploring novelties. All the makers are glued together by a common and shared vision and thus develop different forms of innovation commons.

These FabLab principles provide makers with very simple rules of governance on the way they can pool knowledge and information, which follow the gift-economy principle. This means that if one member enters the community with a problem to address, this member can benefit from the pool of knowledge available if and only if this member is also a producer of part of the solution. Members cannot be passive and simple spectators. For this reason, the use of digital tools, the production of new digital tools or the production of new objects are often considered as means rather than an end in themselves.

Suire (2019) refers to anthropologist Claude LeviStrauss to characterize the ethos of Makers. In La pensée sauvage (The Savage Mind), Levi-Strauss (1962) came up with the fundamental distinction between an engineer mindset and a savage mindset. If the first one is related to a rational, organized thought and, in some sense, is based on the "learn-to-make" principle, the latter comes with the concept of bricolage: a way to produce innova-

1 Fablabs.io tion or novelty using whatever is at hand. To put it simply, the savage mindset and bricolage way of doing are based on a "make-to-learn" principle. Digital tools such as a 3D printer are tools destined primarily to help makers start a project from scratch (Baker and Nelson, 2015). With the 3D printer comes a digital code ${ }^{2}$ that can also be shared and discussed with other makers. In this way, a 3D printer can be considered as a platform from which various makers can coordinate their actions and decisions. But it also supports the development of local innovation commons, which are themselves embedded in a more dispersed and invisible worldwide college of makers. Some feedback loops between makers exist and serve to refine, discuss or drop some intermediary solutions or path developments. All these "understandings gained through experience" (Hess and Ostrom, 2007) can be shared within a community and fuel the innovation commons. Thus, "the common pool resource is not the technology per se, but information and knowledge about the technology that subsequently facilitates its development”, (Allen and Potts, 2016: para. 1).

The innovation commons associated with maker ethos and FabLabs can serve to resolve localized problems (technological, process, products, etc.), whether these problems are sourced from a local ecosystem of innovation, for instance, or simply brought by a maker or entrepreneur. Under such circumstances, a FabLab can act as the locus where the formal and rational mindset associated with engineers can discover and interact with a savage mindset. That is to say that a FabLab may offer an opportunity to blend formal and rigorous ways to address problems with the informal as a creative way to explore alternative solutions.

What is more important is that a Fablab with active makers produces a latent knowledge externality that can be combined with other projects within the locality. It may become, in this sense, a generative middleground plaform. Halbinger (2018) notes that those who attend makerspaces (a variant of a FabLab) are also those who are more innovative in their daily life. The local innovation commons help to develop hard and soft skills around bricolage, prototyping and learning by failing and exploring with others. Once a maker acquires these skills, this maker can re-use them in other situations with uncertain or ambiguous options, for the maker's own interest, for private concerns, or to re-invest these skills in the local innovation commons. When pieces of knowledge are assembled with others, a value can be revealed later on. All this is permitted by a specific governance mechanism with no property

2 Many source codes used to 3D print objects are freely available on websites such as thingiverse.com for instance. 
rights a priori and is based on a gift-economy. It is, to some extent, a guarantee for the local innovation commons' sustainability.

Suire (2019) gives the example of the Bionico Hand ${ }^{3}$ innovation as an ideal type of how local innovation commons can shape a FabLab into a middleground platform. In 2012, several non-professional entrepreneurs localized in the mid-sized French city of Rennes entirely co-produced a myoelectric prosthetic arm for amputees. In less than six months, Nicolas H., an arm amputee and two makers from the local FabLab developed a 3D-printed prototype with an Arduino electronic card, a fishing line and tape. They had no particular prior knowledge related to prosthetic arms apart from their complementary backgrounds and a shared value space. Bricolage could, however, help them to "reach unforeseen results" (LeviStrauss, 1962). They started from existing open-source pieces of knowledge developed through the open-source cyborg project InMoov ${ }^{4}$. This re-use of resources for a new purpose is an important marker of the bricolage mode of innovation (Garud and Karnøe, 2003). Here, InMoov acted as a global knowledge externality that was absorbed and nurtured by the local makers entrepreneurs involved in the project.

Bionico Hand was made possible because an end-user was matched together with two local makers, embedded in a global network of makers. Together, they pooled their respective knowledge, but also shared their ignorance and unknown zones in order to find complements inside this global distributed network of open-source knowledge. On one side, the local FabLab played the role of an intermediary platform helping the makers coordinate local and distant decisions or actions. On the other, the local FabLab was the place where prototyped and intermediary versions of Bionico Hand were co-shaped. This geographical proximity was a necessary condition to trigger the project because all the knowledge manipulated in the first phases was highly tacit.

Svensson and Koss Hartmann (2018) reminds us of how a makerspace can be crucial to conduct some end-user-oriented innovation. In the case of the Bionico Hand, the local FabLab facilitated the entrepreneurial discovery process and the dealing with uncertainties. The size and scope of the epistemic community varied with the project such that the local innovation commons co-evolved with the needs identified as the project moved forward. The enrolment of new game partners from various locations (India, Russia, Brazil, United States, etc.) as well as the

$3 \mathrm{https} / / /$ bionico.org

$4 \mathrm{http}: / /$ inmoov.fr enrolment of formal organizations (University of Pisa, Johns Hopkins University, Berlin FabLab, etc.), including a financial reward from Google, had been facilitated by a strong defense against any kind of enclosure. If complex knowledge around Bionico Hand had been discussed and co-shaped with many actors or entities locally and globally, along with formal and informal stakeholders, a local base remained crucial to finally make decisions to coordinate actions around tacit knowledge and make the project progress. In such a perspective, inasmuch as a FabLab such as the Rennes FabLab, gathers projects and events around a particular place or space, while also facilitating a shared vision and the creation of common values around an innovation in the making, it will play the role of a middleground. This, however, does not guarantee that the FabLab will always constitue a middleground. The local commons provide a stock of knowledge and know-how, as well as a memory of the practices used that can facilitate the sustainability of the middleground, but if no relation with the upperground is observed and/or if there is no output to the project, then the local commons will simply spillover to the local ecosystem.

The whole Bionico Hand project was based on an open-source technology and code. As far as it is was absorbable and understandable by participants, everyone could therefore discuss the solution or the different options without any market considerations in mind. "To participate, you just have to contribute” says Potts (2019). As pointed further by Allen and Potts (2016), the local innovation commons allow to escape from a particular, even locked trajectory, by keeping many alternatives open. In the very early stages of the Bionico Hand project, the absence of property rights was a guarantee for bricolage and learning by experiments. To put it in another way, the Bionico Hand innovation was based on sequential and cumulative small-scale experimentations producing pieces of knowledge. These local experimentations can be considered as one of the pillars of the evolving inclusive innovation commons. When stakeholders of the Bionico Hand project pooled together information and knowledge, they were able to overcome uncertainties.

Processed uncertainty in this way is one of the basic functions of innovation commons (Allen and Potts, 2016). Neither market, nor hierarchies would have been a valuable institutional arrangement at the very earliest stage of this innovation trajectory. The local innovation commons emerge as a complementary institutional context related to those already existing in the locality: accelerators, incubators, fund raisers, and so on, on one side, and formal companies (big and small), on the other. The first are not always capable of supporting projects with such an uncer- 
tain output partly due to the lack of legitimacy of project holders. The second consider that market opportunities are too uncertain to engage internal resources in such a risky project. Therefore, there is no direct competition between different local institutional contexts governing innovation, but rather a complementarity between local innovation commons facilitating the emergence of novelties and the discovery of technological and social opportunities as well as breakthrough innovations. This institutional arrangement can be temporary and can decline either with the end of the project or because contributors to the innovation commons drastically diminish their commitment for personal reasons (other commitments, conflicts about governance, divergence and non-cooperative behavior, opportunism, a controversial market exit, etc.). Whatever the case, collective action around the local creation process produces learning and new knowledge that can be re-used for other projects, that can help bring together different stakeholders and community members, and that can foster a culture of experimentation and innovation.

\section{Discussion}

The aim of this contribution was to highlight the role played by local innovation commons in the dynamics of local knowledge creation, in particular when associated with middleground components. These particular forms of governance, through the integration of communities, local resources and institutional arrangements, favor the articulation of local knowledge and the production, generation, experimentation and validation of new ideas within middlegrounds. Drawing on the works of Elinor Ostrom, we have focused on the building of local innovation commons by an emerging local community of passionate actors who elaborate common institutional arrangements and appropriate governance structures to promote their knowledge creation efforts. Such a communitarian perspective, which is at the origin of the emergence and of the dynamics of middlegrounds, raises, however, several important elements of discussion.

First, if the groups of actors or communities at the origin of the building of the local innovation commons seem to frequently emerge from the underground, bringing together talents from different domains of knowledge (such as electronic enthusiasts, computer amateurs, or digital hackers, but also end-user or amateur citizens, in the case of FabLabs), a more careful investigation of the composition of such communities shows that members of these informal collectives often try to enroll individu- als from the upperground for their joint endeavor to gain legitimacy. In the case of the Homebrew Computer Club, for example, which played an influential role in the development of the microcomputer revolution, highly qualified engineers from Atari or Hewlett Packard were members of the community alongside young enthusiasts and entrepreneurs. Their presence as active members within the community not only contributed to increase the visibility and legitimacy of the middleground, but it also facilitated the possibility to access financial supports and resources from the organizations of the upperground.

Second, the nature of the institutional arrangements is essentially twofold. On one side, there are institutional arrangements destined to pool local resources and to equip the local platforms of interactions (the components of the middleground) with rules and norms to efficiently function in order to facilitate the connections between members and their mutual learning experience. On the other side, there are institutional arrangements destined to facilitate the transformation of ideas discussed and exchanged in the local commons into novelties, innovative outputs, prototypes, up to the formation of start-ups. As an example, the use of business model practices or creative commons are some of the means that can help reach these objectives. The first types of arrangements clearly target the constitution, the maintenance or the resilience of the collective, while the second types of arrangements aim at generating efficient business solutions. These latter arrangements come into being as complementary mechanisms, which help reduce market uncertainty and help create opportunities, but also disappear as these uncertainties are resolved and as opportunities become fully shaped, or, by contrast, as the innovative endeavors fail. As underlined above, such dynamics explain the temporal character of the innovation commons. As start-ups and SMEs emerge from the collective and go into business, the risk is high that the talents at their origin will no longer invest as they did in the past into the local commons. The paradox is thus that the more successful they are in terms of business achievements, the more fragile the local innovation commons, and by extension, the more fragile the middleground. Formal outputs are, however, only one of the possible trajectories associated with local innovation commons. In some situations, local innovation commons can collapse because uncertainties (around problems and solutions) are discovered and remain too high, or because collective commitment decreases. In spite of this, all learnings, cross-learnings and trust (mistrust as well) remain and could be reinvested elsewhere.

Third, it is worth noting that the risks that threaten the local commons could be counterbalanced by the accu- 
mulation of experience of interactions between the different agents who contribute to build a given arrangement. Such accumulation of experience does not vanish, even in the case of failure. The functioning of communities at the basis of these arrangements tend to accumulate and keep these experiences in a form of latent knowledge or collective "creative slack" (Cohendet and Simon, 2007). The notion of creative slack refers to the notion of organizational slack highlighted by Penrose (1959) who suggested that organizations always have a stock of unused or underused resources (e.g., knowledge, relationships, etc.) that inevitably accumulates in the course of developing any given product or service. These unexploited, productive and latent resources constitute a reservoir of potential solutions or practices, but also enhance knowwho and know-how skills for future innovative endeavors. Thus, provided the institutional arrangements that contribute to glue the members of the middleground community together, the formation of the creative slack is an opportunity to increase the generative power of the community and to extend the life cycle of the local innovation commons.

Fourth, another threat that faces local innovation commons - and, again, middlegrounds - is the risk of conflict or divergence between members of the community that could lead to the breakdown of the initial community and to the formation of one or several competing communities for the use of the common resources. The perspective drawn by Ostrom generally refers to only one community, coherent enough to set up institutional arrangements to pool and manage common resources. However, in the case of innovation communities, and more specifically when these communities are embedded within middleground type of platforms, the risk is high of divergence between actors as some collective works succeed in becoming business achievements. For instance, when market considerations conflict with open-source philosophy, clashes between members lead to a fragmentation of space of sharing values.

Fifth, while the above discussions have focused on the local formation of ideas and local pooling of resources within the middleground, the global dimension is inherently associated with the local formation of the commons (especially through spaces and events). As described by the FabLab example, local innovation commons are nurtured by active local informal players, with all of them embedded in a global network of makers. This means that the local innovation commons on which are built middlegrounds evolve with local contributions, but may also benefit from a global knowledge externality, depending on the projects they work on. If projects and places go hand in hand, it is first and foremost the reputation and legitimacy of makers, as individuals, that can guarantee the feedback of the global community. If places and projects are helpful in triggering a common pool of knowledge, success (no matter which form it takes for the community), reputation and signaling are other necessary conditions to accelerate the development of the commons from global networks.

The local commons are at the core of the dynamics of local knowledge creation. Again, places, spaces, projects and events which allow people to meet and experience mutual learning may not always be sufficient to generate opportunities for the community and to drive the innovation dynamics accompanying the locality's growth and development, that is unless equipped with the communities, resources and institutional arrangements out of which and on which local knowledge creation processes are built. Intermediary middleground platforms cannot alone explain what (formal and informal) agents actually do to transform ideas into innovative outputs. This is where, we believe, it is essential to bring together the literature on the middleground with that of the commons. The emergence of novelties facing strong uncertainties is deeply related to the collective ability of members to "organize" local innovation commons, but, as such, the micro-dynamics of interactions within structured and verticalized ecosystems of innovation is still largely unknown, paving the way for a future research agenda.

\section{References}

Allen, D. W., \& Potts, J. (2015). The Innovation Commons - Why it Exists, What it Does, Who it Benefits, and How. June 11 2015. Available at SSRN: https://ssrn.com/abstract=2617141.

Allen, D., \& Potts, J. (2016). How innovation commons contribute to discovering and developing new technologies. International Journal of the Commons, 10(2), 1035-1054.

Allen, R. C. (1983). Collective invention. Journal of Economic Behavior \& Organization, 4(1), 1-24.

Amin, A., \& Cohendet, P. (2004). Architectures of knowledge: Firms, capabilities, and communities. Oxford University Press.

Amin, A., \& Thrift, N. (1992). Neo-Marshallian nodes in global networks. International Journal of Urban and Regional Research, 16(4), 571-587.

Asheim, B. T., \& Gertler, M. S. (2005). The geography of innovation: regional innovation systems. In Fagerberg, J., Mowery, D. \& Nelson, R. (Eds.), The Oxford Handbook of Innovation, pp. 291-317, Oxford, UK: Oxford University Press.

Avdikos, V. (2015). Processes of creation and commodification of local collective symbolic capital; a tale of gentrification from Athens. City, Culture and Society, 6(4), 117-123.

Baker, T., \& Nelson, R. E. (2005). Creating something from nothing: Resource construction through entrepreneurial bricolage. Administrative Science Quarterly, 50(3), 329-366. 
Bathelt, H., \& Glückler, J. (2011). The relational economy: Geographies of knowing and learning. Oxford, UK: Oxford University Press.

Bathelt, H., Malmberg, A., \& Maskell, P. (2004). Clusters and knowledge: local buzz, global pipelines and the process of knowledge creation. Progress in Human Geography, 28(1), 31-56.

Bollier, D., \& Helfrich, S. (Eds.). (2014). The wealth of the commons: A world beyond market and state. Levellers Press.

Capello, R. (1999). Spatial transfer of knowledge in high technology milieux: learning versus collective learning processes. Regional Studies, 33(4), 353-365.

Cohendet, P., \& Simon, L. (2007). Playing across the playground: paradoxes of knowledge creation in the videogame firm. Journal of Organizational Behavior: The International Journal of Industrial, Occupational and Organizational Psychology and Behavior, 28(5), 587-605.

Cohendet, P., Grandadam, D., \& Simon, L. (2010). The anatomy of the creative city. Industry and Innovation, 17(1), 91-111.

Cumbers, A., MacKinnon, D., \& McMaster, R. (2003). Institutions, power and space: assessing the limits to institutionalism in economic geography. European Urban and Regional Studies, 10(4), 325-342.

Cutcher-Gershenfeld, J., \& Lawson, C. (2020). Valuing the Commons: A Fundamental Challenge across Complex System. NSF/SBE 2020 White paper on Future Research in the Social, Behavioral \& Economic Sciences.

Dekker, E. (2020). Book Review: Jason Potts, Innovation Commons: The Origin of Economic Growth, Oxford, UK: Oxford University Press. ISBN: 9780190937508. Journal of Cultural Economics, 44(4), 661-664.

Garud, R., \& Karnøe, P. (2003). Bricolage versus breakthrough: Distributed and embedded agency in technology entrepreneurship, Research Policy, 32(2), 277-300.

Garud, R., \& Van de Ven, A. H. (1989). Technological innovation and industry emergence: The case of cochlear implants. Research on the Management of Innovation, Vol. 5, 489-532.

Gershenfeld, N. (2005). Fab: The coming revolution on your desktop - From personal computers to personal fabrication. New York: Basic.

Grabher, G. (2004). Learning in projects, remembering in networks? Communality, sociality, and connectivity in project ecologies. European Urban and Regional Studies, 11(2), 103-123.

Giuliani, E., \& Bell, M. (2005). The micro-determinants of meso-level learning and innovation: evidence from a Chilean wine cluster. Research Policy, 34(1), 47-68.

Grandadam, D., Cohendet, P., \& Simon, L. (2013). Places, spaces and the dynamics of creativity: The video game industry in Montreal. Regional Studies, 47(10), 1701-1714.

Halbinger M., (2018), The role of makerspaces in supporting consumer innovation and diffusion: an empirical analysis. Research Policy, 47(10), 2028-2036.

Hardin, G. (1968). The tragedy of the commons. Science, 162(3859), 1243-1248.
Hatch, M. (2013). The makers movement manifesto. New York: McGraw-Hill.

Hausmann, R., \& Rodrik, D. (2003). Economic development as self-discovery. Journal of Development Economics, 72(2), 603-633.

Hess, C., \& Ostrom, E. (2007). Understanding knowledge as a commons. From theory to practice. Cambridge, MA: MIT Press.

Lange, B., \& Schüßler, E. (2018). Unpacking the middleground of creative cities: spatiotemporal dynamics in the configuration of the Berlin design field. Regional Studies, 52(11), 1548-1558.

Lévi-Strauss, C. (1962). La pensée sauvage. Paris: Plon.

Lorenzen, M., \& Mudambi, R. (2013). Clusters, connectivity and catch-up: Bollywood and Bangalore in the global economy. Journal of Economic Geography, 13(3), 501-534.

Lundvall, B. Å. (2007). National innovation systems-analytical concept and development tool. Industry and Innovation, 14(1), 95-119.

Markusen, A. (1996). Sticky places in slippery space: a typology of industrial districts. Economic Geography, 72(3), 293-313.

Maskell, P., \& Malmberg, A. (1999). Localised learning and industrial competitiveness. Cambridge Journal of Economics, 23(2), 167-185.

Ostrom, E. (1990). Governing the commons: The evolution of institutions for collective action. Cambridge University Press.

Penrose, E. (1959). The Theory of the Growth of the Firm. Oxford: Basil Blackwell.

Potts, J. (2018). Governing the innovation commons. Journal of Institutional Economics, 14(6), 1025-1047.

Potts, J. (2019). Innovation Commons: The Origin of Economic Growth. Oxford, UK: Oxford University Press.

Saxenian, A. (1994). Regional advantage. Culture and competition in Silicon Valley and Route 128. Cambridge, MA: Harvard University Press.

Simon, L. (2009). Underground, upperground et middle-ground: les collectifs créatifs et la capacité créative de la ville. Management international/Gestiòn Internacional/International Management, 13, 37-51.

Storper, M. (1997). The regional world: territorial development in a global economy. New York/London: Guilford press.

Storper, M. (2005). Society, community, and economic development. Studies in Comparative International Development, 39(4), 30-57.

Suire, R. (2019). Innovating by bricolage: how do firms diversify through knowledge interactions with FabLabs?. Regional Studies, 53(7), 939-950.

Svensson P., \& Koss Hartmann R., (2018), Policies to promote user innovation: Makerspaces and clinician innovation in Swedish Hospitals. Research Policy, 47(1), 277-288.

Tirole, J. (2017). Economics for the common good. Princeton, NJ: Princeton University Press.

Van de Ven, A. H. (1993). A community perspective on the emergence of innovations. Journal of Engineering and Technology Management, 10(1-2), 23-51.

Walter-Herrmann, J., \& Büching, C. (Eds.). (2014). Fablab: Of machines, makers and inventors. Transcript. Wetzlar. 